\title{
MIKROENKAPSULASI OLEORESIN KAYU MANIS (Cinnamomum burmannii) METODE SPRAY DRYING DENGAN PENYALUT MALTODEXTRIN - SUSU SKIM
}

\author{
Mira Nurhayani, Alfi Rohmawati dan Laeli Kurniasari* \\ Jurusan Teknik Kimia, Fakultas Teknik, Universitas Wahid Hasyim \\ Jl. Menoreh Tengah X/22, Sampangan, Semarang 50236. \\ "Email: laelikurniasari@unwahas.ac.id
}

\begin{abstract}
Abstrak
Oleoresin (Cinnamomum burmannii) merupakan senyawa hasil ekstraksi antara rempah rempah yang di ekstrak dengan pelarutnya. Salah satu rempah yang dapat diekstrak adalah kayu manis.. Namun demikian, oleoresin rentan terhadap sinar UV, oksidasi, temperature yang tinggi dan humidity. Sehingga diperlukan proses mikroenkapsulasi agar senyawa oleoresin tidak mudah rusak. Penelitian ini bertujuan untuk mengetahui hasil rendemen dan morfologi dari emulsi dan mikrokapsul oleoresin kayu manis. Mikroenkapuslasi oleoresin dilakukan dengan metode spray drying dengan penyalut maltodextrin - susu skim. Variabel dalam penelitian ini terdiri dari empat rasio maltodextrin-susu skim dari \% volume $(20 \%$ : 0\%, 19,2\%:0,8\%, 18,4\%:1,6\% dan 17,6\%:2,4\%.) dengan oleoresin 5\% dari total bahan penyalut. Hasil rendemen terbaik pada penelitian ini adalah perbandingan campuran maltodextrin-susu skim 19,2\%:0,8\% dengan daya tahan emulsi 70 menit, kadar air 3,5\%, surface oil 5,65\%, dan efisiensi mikrokapsul 44,51\%. Sedangkan morfologi emulsi dan mikrokapsul cenderung berbentuk bulat dan teratur
\end{abstract}

Kata kunci: Kayu manis, Oleoresin, Mikroenkapsulasi, Spray drying

\section{PENDAHULUAN}

Indonesia merupakan negara penghasil kayu manis terbesar di Indonesia. Pada tahun 2011 Indonesia menghasilkan 92.900 ton kayu manis. (Khasanah dkk, 2017). Kayu manis sudah dimanfaatkan sebagai obat - obatan dan bumbu masakan sejak 5000 SM. Kayu manis mempunyai kandungan cyanamaldehide sebanyak $60-70 \%$. Kayu manis yang diekstraksi akan menghasilkan minyak atsiri dan oleoresin. Menurut Arshad dkk (2018) oleoresin merupkan hasil ekstraksi antara rempah - rempah dengan pelarutnya.

Oleoresin mempunyai sifat fisika yang sama dengan bahan asalnya. Oleoresin yang berasal dari kayu manis akan memiliki bau, rasa dan warna mirip kayu manis. Selain itu, kelebihan kayu manis yang di ekstrak menjadi oleoresin adalah bersih, lebih mudah dikontrol dan ekonomis. Namun, oleoresin rentan terhadap sinar UV, oksidasi, temperature yang tinggi dan humidity (Jayanudin dkk, 2016). Sehingga diperlukan proses mikroenkapsulasi agar oleoresin dapat tahan lama dan tidak mudah rusak.

Mikroenkapsulasi merupakan proses perubahan fasa suatu senyawa atau bahan dari bentuk liquid menjadi solid. Mikroenkapsulasi terdiri dari bahan inti dan bahan penyalut (enkapsulan). Salah satu metode yang sering digunakan adalah metode spray drying. Alasan penggunaan metode spray drying selain karena biayanya murah, metode ini pun dapat mudah di scale up (Jamekorshid dkk, 2014).

Selain metode mikroenkapsulasi, bahan penyalut merupakan salah satu bagian yang penting dalam proses ini. Bahan yang biasa digunakan antara lain gum arab, gelati, maltodektrin dan modified starch. Maltodektrin merupakan bahan penyalut dengan kelarutan yang baik. Namun demikian, bahan penyalut yang menggunakan maltodextrin mempunyai kelemahan yaitu tidak mempunyai kemampuan yang baik sebagai pengemulsi (Khasanah dkk, 2015). Kelemahan tersebut dapat diatasi dengan mengkombinasikan bahan lain sebagai penyalut. Bahan yang dapat dikombinasikan dengan maltodextrin salah satunya adalah susu skim.

Susu skim bubuk menurut American Dairy Products Institute adalah produk susu yang dihasilkan dari penghilangan sebagian lemak dan air dari susu yang di pasteurisasi. Menurut Maciel dkk (2014) susu skim dapat dijadikan bahan penyalut yang dapat melindungi bahan inti selama proses mikroenkapsulasi. Lebih lanjut menurut Khasanah (2015) menyatakan bahwa penyalut susu skim dapat mengikat komponen flavor yang di mikroenkapsulasi dan mempunyai kestabilan emulsi yang baik pada larutan bahan penyalut. Penambahan susu skim juga disebutkan dapat memperbaiki hasil 
tampilan mikrostruktur dari oleoresin daun kayu manis (Khasanah dkk, 2015). Beberapa proses mikroenkapsulasi dengan susu skim sebagai salah satu bahan penyalut diantaranya adalah enkapsulasi oleoresin daun kayu manis dengan campuran maltodekstrin, gum arab dan susu skim (Khasanah dkk, 2017) serta mikroenkapsulasi bakteri probiotik dengan campuran susu skim dan maltodekstrin (Sumanti DM dkk, 2016).

Susu skim sebagai bahan kombinasi penyalut dengan maltodextrin harus mempunyai perbandingan komposisi yang tepat agar dihasilkan mikrokapsul yang baik. Oleh karena itu penelitian ini bertujuan untuk mengetahui rendemen dan morfologi dari mikrokapsul oleoresin kayu manis dari setiap perbandingan bahan penyalut.

\section{METODOLOGI}

\section{Bahan dan Alat}

Bahan utama dari penelitian ini adalah oleoresin kayu manis yang diekstrak dari kayu manis yang diperoleh dari Pasar Bulu. Pengekstrak yang digunakan adalah etanol $85 \%$ yang diperoleh dari PT Brataco Chemical Indonesia. Sedangkan untuk bahan penyalut yang digunakan adalah maltodextrin yang diperoleh dari Toko Indrasari dan susu skim yang diproduksi oleh PT. Nutrifood Indonesia. Bahan lainnya untuk analisa yaitu $\mathrm{N}$-hexane yang diperoleh dari Toko indrasari.

Sedangkann untuk alat utama yang digunakan adalah neraca analitik, homogenizer, MAE, Rotary Evaporator, Spray dryer, soxhlet dan mikroskop binokuler.

\section{Preparasi Bahan Baku}

Kayu manis dikeringkan dalam oven selama 2 jam pada suhu $40^{\circ} \mathrm{C}$. Kayu manis yang sudah kering kemudian di crusher dan di screening dengan ukuran 80 mesh.

\section{Ekstraksi Kayu Manis}

Serbuk kayu manis sebanyak 10 gram diekstrasi dengan etanol $85 \%$ menggunakan MAE (Microwave Assisted Extractor) selama 23 menit dengan daya $30 \%$.

\section{Pembuatan Emulsi}

Maltodextrin dan susu skim dengan perbandingan $20 \%: 0 \%, 19,2 \%: 0,8 \%, 18,4 \%$ : $1,6 \%$ dan $17,6 \%: 2,4 \%$ dilarutkan dalam 300 $\mathrm{ml}$ aqudes. Kemudian homogenkan larutan tersebut dengan menggunakan homogenizer kecepatan 5.200 rpm selama 5 menit. Selanjutnya masukan oleoresin sebanyak 4 gram yang telah dilarutkan dalam $100 \mathrm{ml}$ aquades. Homogenkan larutan tersebut dengan homogenizer kecepatan $6.400 \mathrm{rpm}$ selama 20 menit.

\section{Pembuatan Mikrokapsul}

Memasukan emulsi yang telah dibuat kebagian umpan dari spray drying. Atur suhu inlet spray drying sekitar $140^{\circ} \mathrm{C}$ kemudian tekan tombol flowrate. Tunggu proses mikrownkapsulasi selesai Simpan mikrokapsul didalam wadah tertutup untuk dianalisa.

\section{Analisa Morfologi Emulsi}

Ambil emulsi dengan menggunakan pipet tetes. Teteskan sedikit emulsi ke permukaan kaca preparat. Kemudian analisa dengan menggunakan mikroskop binokuler perbesaran $20 x$.

\section{Analisa Kadar Air}

Timbang 2 gram mikrokapsul oleoresin kemudian keringkan dalam oven pada suhu 100 $-105^{\circ}$ C. Timbang sampel sampai konstan.

\section{Analisa Surface Oil}

Timbang 2 gram mikrokapsul oleoresin dan masukan kedalam kertas saring halus. Cuci mikrokapsul oleoresin dengan n-hexane $30 \mathrm{ml}$ sebanyak 3 kali.

\section{Efisiensi Mikrokapsul}

Efisiensi mikrokapsul yang didapat dihitung dengan menggunakan persamaan dalam jurnal Shanmugasundaram (2008) :

$$
\mathrm{EE}(\%)=\frac{\text { Total oleoresin }}{\text { Oleoresin yang digunakan }} \times 100 \%
$$

\section{Analisa SEM (Scanning Electron Microscopy)}

Analisa SEM (Scanning Electron Microscopy) dilakukan dengan menggunakan SEM JEOL tipe JSM 6510 LA.

\section{HASIL DAN PEMBAHASAN}

\section{Morfologi Emulsi Oleoresin}

Morfologi dari emulsi oleoresin dapat dilihat dengan menggunakan mikroskop metalograf dengan perbesaran $20 \mathrm{x}$. Analisa ini dilakukan untuk mengetahui bentuk dan ukuran partikel dari emulsi oleoresin yang akan di serbukkan. Hasil morfologi emulsi tersaji pada Gambar 1. 

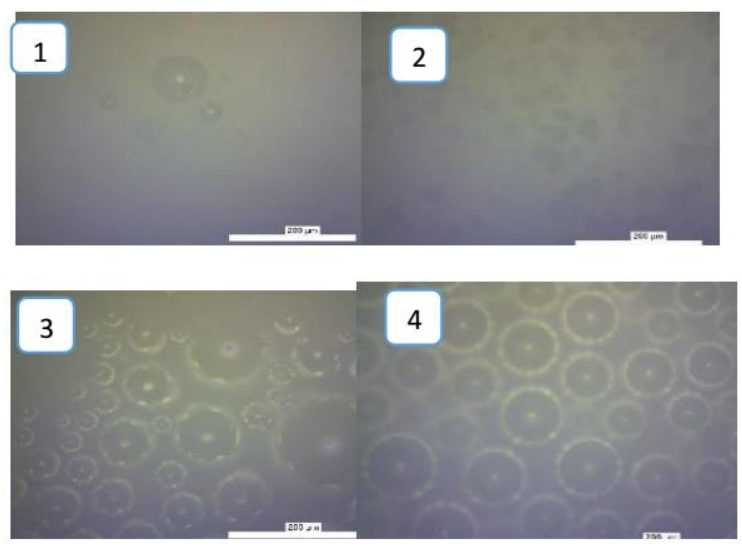

Ket $: 1$ = perbandingan maltodextrin dan susu skim 20\%: $0 \% \mathrm{~g}, 2=$ perbandingan maltodextrin dan susu skim 19,2\%:0,8\% g, $3=$ perbandingan maltodextrin dan susu skim 18,4\%:1,6\% g serta $4=$ perbandingan maltodextrin dan susu skim 17,6\%: $2,4 \% \mathrm{~g}$.

\section{Gambar 1. Morfologi Emulsi Oleoresin Kayu Manis}

Menurut penelitian yang dilakukan oleh Nurhasanah, dkk (2011) suatu emulsi dengan konsentrasi yang tinggi (kental) akan menghasilkan ukuran globula yang kecil. Sementara untuk konsentrasi yang rendah (encer) akan dihasilkan morfologi seperti sponge yang berpori.

Berdasarkan Gambar 1 menyatakan bahwa sampel nomor 1, 3 dan 4 mempunyai morfologi berupa globula berukuran relative kecil. Morfologi ini disebabkan karena sampel viskositas yang relative lebih tinggi dibandingkan dengan sampel nomor 2. Pada sampel nomor 2, morfologi yang terbentuk berupa sponge. Sedangkan pada sampel nomor 1 terdapat 2 buah globula dengan ukuran yang berbeda. Hal ini disebabkan karena sifat maltodextrin (enkapsulan) sebagai emulsi yang kurang stabil dibandingkan dengan campuran maltodextrin - susu skim.

\section{Kadar Air}

Kadar air merupakan parameter yang mempengaruhi shelf life dari mikrokapsul yang terbentuk. Pada Gambar 2 menyatakan bahwa persentase kadar air untuk ke 4 sampel mengalami fluktuasi. Fluktuasi ini disebabkan oleh viskositas masing - masing bahan penyalut. Dimana semakin tinggi viskositas penyalut maka kadar air yang diperoleh akan akan semakin tinggi (Khasanah dkk, 2015).

Nilai kadar air tertinggi diperoleh dari sampel nomor 1 dengan penyalut berupa maltodextrin sebesar 5,8\%. Grafik diatas juga menunjukan nilai kadar air terkecil diperoleh dari sampel nomor 2 sebesar 3,5\%. Sementara untuk nomor sampel 3 dan 4 nilai kadar air berturut - turut sebesar 5,6\% dan 4,4\%. Secara keseluruhan, kadar air yang didapat pada penelitian memenuhi syarat kadar air $2-6 \%$ untuk mikrokapsul. Maka mikrokapsul oleoresin kulit kayu manis dapat disimpan dalam waktu yang lebih lama.

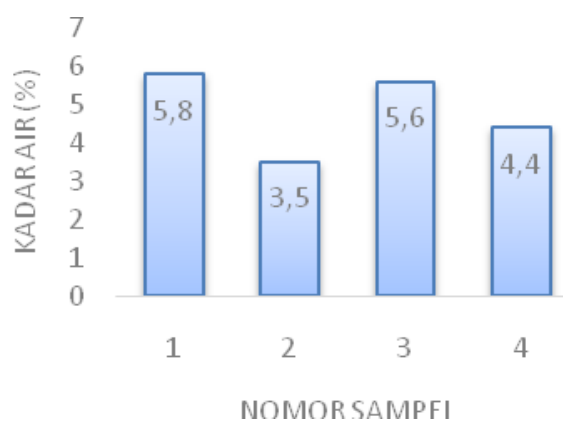

Ket : $1=$ perbandingan maltodextrin dan susu skim 20\%: $0 \% \mathrm{~g}, 2=$ perbandingan maltodextrin dan susu skim 19,2\%:0,8\% g, $3=$ perbandingan maltodextrin dan susu skim 18,4\%:1,6\% g serta $4=$ perbandingan maltodextrin dan susu skim $17,6 \%$ : $2,4 \% \mathrm{~g}$.

\section{Gambar 2. Persentase Kadar Air}

\section{Surface Oil}

Surface oil merupakan jumlah minyak yang berada dipermukaan mikrokapsul. Pada Gambar 3 menunjukan nilai surface oil tertinggi pada sampel nomor 1 sebesar $40,95 \%$ dengan penyalut maltodextrin. Sementara untuk sampel dengan nomor 2 sampai 4 mengalami penurunan yang cukup signifikan. Persentase surface oil dari ketiga sampel tersebut berturut - turut adalah 5,65\%, 18,4\% dan 25,1\%. Penyalut yang digunakan adalah campuran maltodextrin dan susu skim.

Penurunan yang terjadi pada sampel nomor 2 sampai 4 disebabkan karena pengaruh penambahan susu skim sebagai bahan penyalut. Menurut Maciel dkk (2016) menyatakan bahwa susu bubuk dapat mengalami aglomerasi karena sifatnya yang higroskopis.

Menurut Nurlaili, dkk (2014) viskositas emulsi yang terlalu tinggi akan menyebabkan proses atomisasi pada spray dyring menjadi sulit sehingga banyak oleoresin yang keluar dan tidak terkapsulkan. 


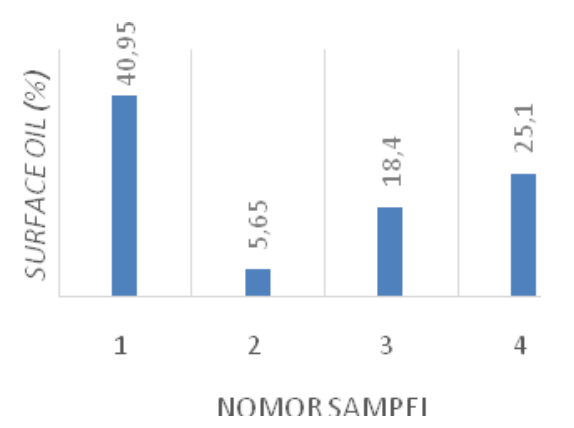

Ket : 1 = perbandingan maltodextrin dan susu skim 20\%: $0 \% \mathrm{~g}, 2=$ perbandingan maltodextrin dan susu skim 19,2\%:0,8\% g, $3=$ perbandingan maltodextrin dan susu skim 18,4\%:1,6\% g serta $4=$ perbandingan maltodextrin dan susu skim $17,6 \%$ : $2,4 \% \mathrm{~g}$.

\section{Gambar 3. Persentase Surface Oil}

\section{EFISIENSI MIKROKAPSUL}

Efisiensi mikrokapsul menunjukan persentase senyawa aktif yang dapat disalut dalam mikrokapsul. Persentase yang didapat pada sampel 1 sampai 4 berturut - turut adalah $41,56 \%, 44,51 \%, 44,46 \%$ dan 47,19\% (Gambar 4).

Menurut Isriany (2012) semakin tinggi konsentrasi bahan penyalut maka efisiensi yang dihasilkan akan semakin tinggi. Namun hal ini tidak berlaku untuk sampel nomor 3. Pada sampel nomor 3 , persentase yang didapat tidak berbeda jauh dengan persentase nomor 1,2 dan 4. Penurunan persentase efisiensi tersebut dapat disebabkan karena waktu disperse yang tidak seragam.

\section{HASIL ANALISA SEM}

Mikrokapsul yang dianalisa menggunakan perbesaran 1000 dengan bentuk granul sekitar $10 \mu \mathrm{m}$. Analisa ini dilakukan dengan menggunakan SEM JEOL tipe JSM 6510 LA (Gambar 5).

Hasil analisa SEM (Scanning Electron Microscopy) menunjukan morfologi granul dari sampel 1 mempunyai granul berbentuk bulat tidak beraturan dengan ukuran yang berbeda. Bulatan tersebut terdapat beberapa kerutan di permukaan granulnya. Hal ini disebabkan karena penyalut maltodextrin tidak mempunyai kemampuan yang baik sebagai emulsi (Khasanah dkk, 2015). Sementara itu, menurut Edris dkk (2016) terkait ketidakseragaman ukuran partikel ini dikarenakan viskositas emulsinya tinggi.

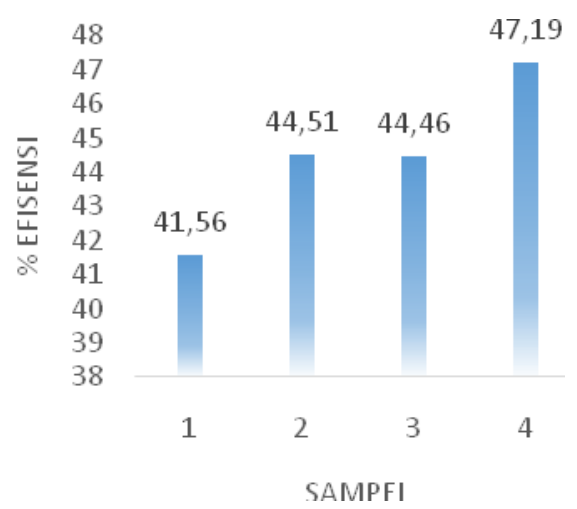

Ket : 1 = perbandingan maltodextrin dan susu skim 20\%: $0 \% \mathrm{~g}, 2=$ perbandingan maltodextrin dan susu skim 19,2\% : 0,8\% g, $3=$ perbandingan maltodextrin dan susu skim 18,4\%:1,6\% g serta $4=$ perbandingan maltodextrin dan susu skim $17,6 \%$ : $2,4 \% \mathrm{~g}$.

\section{Gambar 4 Persentase Efisiensi Mikrokapsul}
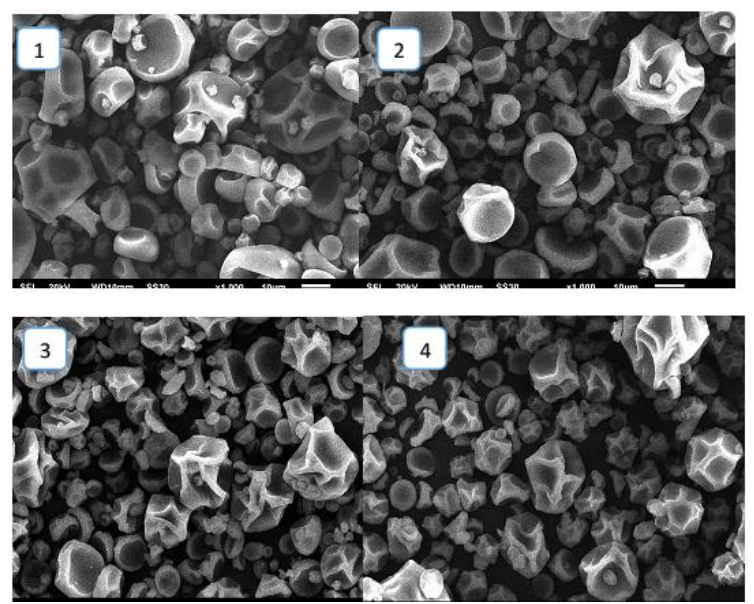

Ket : 1 = perbandingan maltodextrin dan susu skim 20\%: $0 \% \mathrm{~g}, 2=$ perbandingan maltodextrin dan susu skim 19,2\% : $0,8 \% \mathrm{~g}, 3=$ perbandingan maltodextrin dan susu skim $18,4 \%: 1,6 \%$ g serta $4=$ perbandingan maltodextrin dan susu skim 17,6\%: $2,4 \% \mathrm{~g}$.

\section{Gambar 5. Morfologi Mikrokapsul Oleoresin}

Pada sampel nomor 2, morfologi mikrokapsul cenderung bulat dengan ukuran yang relative sama. Penampakan mikrokapsul nomor 2 terlihat lebih bagus dibandingkan ketiga sampel lainnya. Hal ini dikarenakan morfologi mikrokapsulnya hanya sedikit yang mengkerut. Menurut Khasanah dkk (2015) mikrokapsul yang mempunyai sedikit kerutan menandakan bahan aktif terkapsul dengan baik. Sementara untuk sampel 3 dan 4 mempunyai morfologi yang semakin mengkerut. Hal ini 
menandakan bahan inti tidak terkapsul dengan baik.

\section{KESIMPULAN}

Berdasarkan hasil peneltian mikroenkapuslasi oleoresin kayu manis dengan penyalut maltodextrin-susu skim metode spray daying yang telah dilakukan maka didapat variable terbaik dalam penelitian ini pada sampel nomor $2(19,2 \%$ : $0,8 \%)$.

\section{DAFTAR PUSTAKA}

Arshad, Hira, Tahira Mohsin Ali, Abid Hasnain, 2018, Native and Modified Sorgum Starches as Well Materials in Microencapsulation of Nutmeg Oleoresin. University of Karachi.Pakistan.

Edris, Amr E, Danuta Kalemba, Adamiec, Marcin Piatkowski, 2016, .Microencapsulation of Nigella Sativa Oleoresin by Spray Drying for Food and Nutraceutical applications.

Isriany,Guslina, 2012, Optimasi Evaluasi Mikroenkapsulasi Medroksipodesteron Asetat Tersalut Poli ( $\varepsilon$-Kaprolakton)-Lilin Lebah..Institut Pertanian Bogor.

Jamekorshid.A, S.M Sadrameli. M Farid, 2014, A Review of Microencapsulations Method of Phase Change Materials (PCMs) As a Thermal Energy Storage (TES) Medium, Renewable and Sustainable Energy Reviews.

Jayanudin, Rochmadi, Meri Yulianti, Ahmad Imanudin, Tri Rina Sari, 2016, Kinetika Release Mikrokapsul Oleoresin Jahe Merah, Jurnal Reaktor.

Khasanah, Lia Umi, Baskara Katri Anandhito, Titiek Rahmawaty, Rohula Utami, Godras Jati Manuhara, 2015, .Pengaruh Rasio Bahan Penyalut Maltodextrin, Gum Arab, dan Susu Skim Terhadap Karakteristik Fisik dan Kimia Mikrokapsul Oleoresin Daun Kayu Manis (Cinnamomum Burmannii), Agritech Vol 35 No. 4

Khasanah, Lia Umi, Baskara Katri Anandhito, Qurothul Uyun, Rohula Utami, 2017, Optimasi Proses Ekstraksi dan Karakterisasi Oleoresin Daun Kayu Manis (Cinnamomum Burmannii) Dua Tahap, Universitas Sebelas Maret.Surakarta.

Maciel. G.M, K.S. Chaves, C. R. F. Grosso,M.L.Gigante, 2014, Microencapsulation of Lactobacillus Achidophillus La- 5 by Spray Drying Using Sweet Whey and Skim Milk as
Encapsulating Materials, University of Campinas.Brazil.

Nurhasanah.S, Komari, Hariyadi P, Budijanto, 2011, Mikroenkapsulasi Minyak Kaya DHA Untuk Fortifikasi Pada Makanan, Institut Pertanian Bogor.

Nurlaili, Fatchul Anam, Purnama Darmadji, Yudi Pranoto, 2014, Mikroenkapsulasi Oleoresin Ampas Jahe (Zingiber Officinale var.Rubrum) dengan Penyalut Maltodextrin, Universitas Gajah Mada.Yogjakarta

Shanmugasundaram, S., 2008, Studies on Microencapsulation of Ginger and Paprika Oleoresin by Spray Drying Tehnique and Analysis of Microstructural characteristics of Encapsulated Oleoresin Powder., Tamil Nadu Agricultural University. India.

Sumanti, DM, Lanti I, Hanidah I, Sukarminah E, Giovanni A, 2016, Pengaruh Konsentrasi Susu Skim dan Maltodekstrin sebagai Penyalut Terhadap Viabilitas dan Karakteristik Mikroenkapsulasi Suspensi Bakteri Lactobacillus plantarum Menggunakan Metode Freeze Drying, Jurnal Penelitian Pangan Vol 1.1 